\title{
Perinatal Outcome of Macrosomic Births in Port Harcourt
}

\author{
Ojule, JD MB,BS, FWACS, Fiebai PO MB,BS, FWACS, FICS, Okongwu C MB,BS, FWACS
}

Department of Obstetrics \& Gynaecology, University of Port Harcourt Teaching Hospital, Port Harcourt.

\begin{abstract}
Background: Macrosomic babies are at increased risk of adverse perinatal outcome and therefore constitute a high risk group of neonates and the incidence appears to be rising. The objective was to determine the incidence of fetal macrosomia, and the perinatal outcome of macrosomic babies, compare with matched term, appropriate weight neonates in the booked antenatal population of the UPTH.
\end{abstract}

Methods: It was a- one year prospective study of the perinatal outcome of singleton babies whose birth weights were $4000 \mathrm{~g}$ and above (macrosomia) delivered to booked antenatal mothers in UPTH between $1^{\text {st }}$ October 2003 and $30^{\text {th }}$ September 2004, comparing them with term appropriate (2500-3999g) weight babies. The birth weight, sex, perinatal and maternal complications documented from direct observations, questioning and other information extracted from patients' case notes, were entered into a personal computer, analysed and presented as frequency tables, percentages, Chi-square $x^{2}$, calculated as appropriate using Epi info version 3.4.3 statistical soft ware. $P<0.05$ was considered statistically significant.

Results: Fetal macrosomia occurred in 354 out of 2417 singleton term deliveries, giving an incidence of 1 in 7 deliveries or $14.65 \%$. The birth asphyxia $7.90 \%$ vs $2.60 \%, p=0.011)$, Neonatal admission (29.54\% vs $2.85 \%, p=0.001)$ and perinatal mortality (48/1000 vs $23 / 1000$ births, $p=0.001)$, caesarean delivery $(55.70 \%$ vs $18.64 \%, p=0.001)$ rates were significantly higher in the macrosomic than the control group.

Conclusion: There is a high incidence of fetal macrosomia in Port Harcourt with associated relatively higher adverse perinatal outcome compared to singleton term normal weight babies.

Keywords: Fetal macrosomia, incidence, perinatal outcome, perinatal mortality, Port Harcourt.

Date Accepted for Publication: $30^{\text {th }}$ August 2010

NigerJMed 2010: 436 - 340

Copyright@2010 Nigerian Journal of Medicine

\section{Introduction}

The establishment of a widely acceptable definition for fetal macrosomia has remained largely controversial and as such has variously been described as actual birth weight $=4 \mathrm{~kg},=4.2 \mathrm{~kg},=4.5 \mathrm{~kg},=5 \mathrm{~kg}$, or estimated birth weight of $4.5 \mathrm{~kg}$ and above. ${ }^{1-6}$

While some authors have used population specific growth curves to classify babies with birth weight above the $90^{\text {th }}$ percentile or birth weight above 2 standard deviations as macrosomia, ${ }^{6.9}$ the American college of Obstetricians and Gynecologists defined it as neonates with an absolute birth weight greater than $4.5 \mathrm{~kg}$ irrespective of gestational age or other demographic variables. $^{10}$

Irrespective of the criteria used for diagnosis, macrosomic fetuses have been reported to be at increased risk of adverse perinatal outcome, including brachial plexus injuries, shoulder dystocia, hypoglycemia, birth asphyxia, neonatal admission and even death. ${ }^{11}$ Maternal complications are often related to cephalopelvic disproportion and include prolonged labour, labour augmentation, operative delivery including caesarean section, infection, perineal laceration, thromboembolic phenomena and anaesthetic accidents. ${ }^{10-13}$

The associated risk factors are well documented and include maternal obesity, diabetes mellitus, multiparity, previous macrosomic deliveries, male fetus, prolonged pregnancy, advanced maternal age, ethnicity, excessive maternal pregnancy weight, and increased inter pregnancy interval. ${ }^{10,12,14}$ Seasonal variations have also been noted with tendency to cluster around the wet season. ${ }^{15}$

The optimal mode of delivery of macrosomic fetuses, in reducing the adverse perinatal outcome, has also remained controversial for decades, ${ }^{15}$ with the pendulum swinging between elective caesarean section, induction of labour and expectant management. ${ }^{2,5}$ Early induction of labour in suspected macrosomia aimed at reducing subsequent morbidity associated with spontaneous vaginal delivery at term 
has not been found to reduce caesarean section rate, instrumental delivery or perinatal morbidity. ${ }^{16}$ On the other hand, elective caesarean births advocated by some authors, ${ }^{2,17}$ have been criticized, as this may warrant a large number of unnecessary caesarean sections to prevent a single bad outcome in suspected macrosomic pregnancies, since some can be delivered vaginally with low rates of maternal and neonatal complications. ${ }^{18}$

This study was therefore carried out to determine the incidence of fetal macrosomia and to compare the perinatal outcome of macrosomic babies with that of singleton term appropriate weight controls, irrespective of their mode of delivery, at the University of Port Harcourt teaching Hospital (UPTH), Port Harcourt.

\section{Patients and methods}

It was a-1 year prospective study between $1^{\text {st }}$ October 2003 and $30^{\text {th }}$ September 2004. Ethical approval was given by the University of Port Harcourt Teaching Hospital Ethics committee.

Babies whose birth weights were $=4000 \mathrm{~g}$ (macrosomia) delivered to booked antenatal mothers in UPTH within this period were recruited for the study. For each macrosomic baby, the next baby in sequential order with normal birth weight $(2500 \mathrm{~g}-3999 \mathrm{~g})$, was also recruited and served as control, after obtaining verbal consent from the mother. Babies of multiple pregnancies, unbooked and non consenting mothers were excluded. Patients with uncertain last menstrual period with no early ultrasound scan dating were also excluded from the study.

All babies were weighed naked by a trained nurse/midwife within 1 hour of birth, using the waymaster scale which was checked daily for zero error and its reliability with known weight.

The Apgar scores were assessed in 1 and 5 minutes of birth and documented by the midwife or the attending physician using the conventional five parameters each with 0 -2 scores, giving a minimum of 0 and maximum of 10. After delivery, each baby was given routine care and resuscitation as indicated by the baby's clinical condition. All babies with low Apgar scores $(<6)$ at 5 minutes, were admitted to the intensive care baby unit (SCBU). Also, babies of diabetic mothers and those whose birth weights were $=4500 \mathrm{~g}$, were routinely admitted into SCBU. The control babies were either admitted into the nursery or sent to the lying-in ward depending on their clinical condition. The weight, sex, perinatal complications and the fate of both groups of neonates were documented.

Obstetric data of the mother such as age, educational status, parity, gestational age, previous obstetric history, details of labour and complications and mode delivery were obtained directly from each parturient and or extracted from their case records. All the information was fed into a personal computer, analyzed and presented as tables, standard deviations, mean, percentages, Chi-square $x^{2}$, Fishers' exact test, relative risk(RR), calculated as appropriate using Epi info version 3.4.3 statistical software. $P<0.05$ was considered statistically significant.

\section{Results}

Three hundred and fifty four (354) of the two thousand four hundred and seventeen thousand $(2,417)$ singleton term deliveries within the study period were macrosomic babies, giving an incidence of 1 in 7 deliveries or $14.65 \%$.

\section{Fetal characteristics}

Amongst the macrosomic babies, 210 were males, and 144 were females, giving a male to female ratio of 3:2. This was statistically significant as $x^{2}=8.24, P=0.04$.

The birth weight of macrosomic babies ranged from 4000 to $6550 \mathrm{~g}$ with a mean \pm SD of $4267 \mathrm{~g} \pm 315 \mathrm{~g}$, as shown in table I. The heaviest female baby weighed $6550 \mathrm{~g}$ delivered by emergency caesarean section at term to a-36 year old diabetic, para 2 mother whose 2 previous babies were macrosomic. This was closely followed by a $6500 \mathrm{~g}$ fresh female stillborn, delivered by emergency caesarean section at term to a -31 year old diabetic multiparous mother. These two patients were earlier scheduled for elective caesarean delivery, but defaulted and instead presented in labour. The three heaviest males each weighed $5100 \mathrm{~g}$, one delivered by emergency caesarean section for failed vacuum, and the other 2 by spontaneous vaginal delivery at term.

\section{Perinatal morbidity}

Table II shows the perinatal complications. The birth asphyxia rate $(1$ minute Apgar score < 6$)$ in the macrosomic group was $7.9 \%$ compared to the control group with $2.6 \%$, as shown in table. This was statistically significant as $x^{2}=10.58, p=0.0114$.

Also, the rate of SCBU admission, $29.54 \%$ in the macrosomic group compared to the control $(2.85 \%)$ was statistically significant as $x^{2}=69.12, p=0.0001$. 
Though, there were cases of clavicular fracture and of shoulder dystocia, surprising, no case of fetal nerve injury was encountered.

\section{Perinatal mortality}

The perinatal mortality among macrosomic babies was two times higher than in the control babies. There were a total of 17 perinatal deaths amongst the macrosomic cases, giving a perinatal mortality rate of 48 in 1000 births, while the control babies had a death rate of 23 in 1000 live births. This was statistically significant as $x^{2}=$ 43.87, $p=0.001$, as shown also in table II.

Two of the perinatal deaths in macrosomic group were stillbirths, while 15 died within the first seven days of life. Fifteen of the macrosomic deaths were males, 2 females, while 6 of the control deaths were males, and 2 , females.

Causes of mortality in the macrosomic babies were birth asphyxia (8), neonatal sepsis and jaundice (5), and undetermined causes in 4. In the control group, birth asphyxia was responsible for deaths in 5 , while neonatal sepsis and jaundice was responsible for deaths in 2, and hemorrhagic disease of the new born in one.

\section{Maternal socio-demographic characteristics}

The age range of mothers of macrosomic babies was 20 - 41 years, with a mean $\pm S D$ of $30.1 \pm 4.15$ years, while the mean age of mothers of the control neonates was $29.9 \pm 4.2$ years, with a range of 18 to 42 years. This was not statistically significant as $X^{2}=0.02, p=$ 0.9005 . Over $98 \%$ of the mothers in both groups had formal education, while less $2 \%$ did not have.

Table III shows that the maternal parity ranged from 0 7. Primigravid and primiparous mothers were each 97 in number, representing $27.4 \%$ each, while para 2 to 4 accounted for $146(41.2 \%)$ of the cases. Only 14 $(3.95 \%)$ were grandmultiparous. The modal parity range was 2 to 4 .

\section{Labour complications}

Table IV depicts complications in labour. There were $78(22.2 \%)$ of cephalopelvic disproportion in labour as against $31(8.75 \%)$ in the control group. This was statistically significant. Also fetal distress, shoulder dystocia perineal laceration and primary post partum haemorrhage were significantly higher in the macrosomic than the control group.
Diabetes mellitus, prolonged pregnancy and abnormal lies and presentations were comparatively higher in mothers of macrosomic babies than mothers of normal weight neonates.

\section{Mode of delivery}

Table V illustrates the mode delivery. Only 166 (46.9\%) mothers with macrosomic fetuses had spontaneous vaginal delivery compared to 288 of the control mothers, with $7(2 \%)$ requiring instrumental vaginal delivery. One hundred and forty-nine (42.1\%) of the mothers of macrosomic babies had emergency caesarean section, compared to $40(11.33 \%)$ in the control group. This was statistically significant as $x^{2}=$ 50.36, $p=0.001$.

Thirty one $(8.8 \%)$ of the macrosomic babies were delivered by elective caesarean section, while 149 $(42.1 \%)$ were delivered by emergency caesarean section. Overall caesarean section rate was $55.7 \%$ in macrosomic pregnancies, compared to $18.64 \%$ in control mothers, also statistically significant as $x^{2}$ $=33.76, p=0.001$, with $R R=1.97$ (1.55-2.51).

One $(0.3 \%)$ of the macrosomic babies was delivered by craniotomy for intra uterine fetal death and another by laparotomy for ruptured uterus in a parturient with a previous caesarean scar. These were not statistically significant as Fisher's exact test $=0.5007$

Table I. Distribution of macrosomic babies by birth weight categories and by sex.

\begin{tabular}{lllcccc}
\hline Birth weight(g) & \multicolumn{2}{c}{ Male } & \multicolumn{2}{c}{ Female } & \multicolumn{2}{c}{ Both sexes } \\
Groups & No. & $\%$ & No. & $\%$ & No. & $\%$ \\
\hline $4000-4499$ & 162 & 77.14 & 120 & 57.14 & 282 & 79.66 \\
$4500-4999$ & 30 & 14.28 & 15 & 7.14 & 45 & 12.71 \\
$5000-5499$ & 18 & 8.58 & 7 & 3.33 & 25 & 7.06 \\
$5500-5999$ & 0 & 0 & 0 & 0 & 0 & 0 \\
$6000-6499$ & 0 & 0 & 0 & 0 & 0 & 0 \\
$6500-6599$ & 0 & 0 & 2 & 0.95 & 2 & 0.56 \\
Total & 210 & 100 & 144 & 100 & 354 & 100 \\
\hline
\end{tabular}

Table II. Perinatal outcome

\begin{tabular}{lccccc}
\hline Outcome & Cases & $\%$ & control & $\%$ & p-value \\
\hline $\begin{array}{l}\text { Birth asphyxia } \\
\text { (AS<6) }\end{array}$ & 28 & 7.91 & 8 & 2.65 & 0.011 \\
Clavicular \# & 2 & 0.56 & 0 & 0 & 0.157 \\
Congenital & & & & & \\
Malformation & 4 & 1.30 & 0 & 0 & 0.461 \\
SCBU admission & 106 & 29.94 & 10 & 2.82 & 0.001 \\
Stillbirths & 2 & 0.56 & 1 & 0.28 & 0.181 \\
1st week deaths & 15 & 3.74 & 7 & & 0.001 \\
Perinatal mortality & $48 / 1000$ & & & $23 / 1000$ & 0.001 \\
\hline
\end{tabular}

Table III. Parity distribution of mothers

\begin{tabular}{ccccc}
\hline Parity & Cases & $\%$ & Control & $\%$ \\
\hline 0 & 97 & 27.4 & 121 & 34.18 \\
1 & 97 & 27.4 & 93 & 26.27 \\
$2-4$ & 146 & 41.20 & 120 & 3.90 \\
e5 & 14 & 4.0 & 20 & 5.65 \\
Total & 354 & 100 & 354 & 100 \\
\hline
\end{tabular}


Table IV. Labour complications

\begin{tabular}{lcccc}
\hline Complication & Cases & $\%$ & Control & $\%$ \\
\hline Cephalopelvic & 78 & 22.2 & 31 & 8.75 \\
$\begin{array}{l}\text { Disproportion } \\
\text { Fetal Distress }\end{array}$ & 30 & 8.70 & 10 & 2.82 \\
$\begin{array}{l}\text { Shoulder Dystocia } \\
\text { Perineal }\end{array}$ & 4 & 1.13 & 0 & 0.00 \\
$\begin{array}{l}\text { Laceration } \\
\begin{array}{l}10 \text { post partum } \\
\text { haemorrhage }\end{array}\end{array}$ & 30 & 8.45 & 16 & 4.45 \\
\begin{tabular}{l} 
Uterine Rupture \\
\hline
\end{tabular} & 1 & 5.60 & 5 & 1.41 \\
\hline
\end{tabular}

\section{Table V. Mode of delivery}

\begin{tabular}{lccccc}
\hline Mode & Cases & $\%$ & Control & $\%$ & p-value \\
\hline $\begin{array}{l}\text { Spontaneous } \\
\text { Vaginal delivery }\end{array}$ & 166 & 46.9 & 261 & 73.73 & 0.0002 \\
$\begin{array}{l}\text { Instrumental } \\
\text { Vaginal delivery }\end{array}$ & 7 & 2.0 & 10 & 2.82 & 0.4720 \\
$\begin{array}{l}\text { Elective Caesarean } \\
\text { section }\end{array}$ & 31 & 8.8 & 33 & 9.38 & 0.8107 \\
$\begin{array}{l}\text { Emergency caesarean } \\
\text { section } \\
\text { Destructive delivery } \\
\text { Total }\end{array}$ & 149 & 42.1 & 40 & 11.33 & 0.0000 \\
& 1 & 0.3 & 0 & 0 & 0.3176 \\
\hline & 354 & 100 & 354 & 100 & \\
\hline
\end{tabular}

\section{Discussion}

The incidence of fetal macrosomia in this study was $14.6 \%$. This is much higher than the figures reported in several other studies, which ranged between 1.3$13 \%{ }^{2,4,5,12,15,19,20}$ The disparity may be due to time interval between the various studies. This is supported by the finding in recent local and Caucasian studies which demonstrated trends towards higher mean birth weights and increased incidence of large for gestational age (LGA) babies attributed to improvement in the socioeconomic environment and concurrent increases in maternal body mass index. ${ }^{21,22}$

The difference could also be due to different criteria used in defining fetal macrosomia in the various studies, difference in the incidence of potential diabetics in the populations studied, and our diet here now changing towards that of western countries with fast food gradually taken over our traditional meals especially in metropolitan cities like Port Harcourt.

The male preponderance of macrosomic babies noted in this series was in keeping with reports of other investigators, which have also been noted as a risk factor for macrosomia. ${ }^{2,8,15,23}$. This relatively higher birth weights of male babies have been attributed to a poorly defined influence of chromosome $Y$, which establishes the antigenic dissimilarity that enhances trophoblastic invasion and which consequently enhances fetal growth. ${ }^{24}$ It has also been speculated that the male fetus tend to have greater lean body mass and less body fat than the female probably due to the effect of fetal testosterone production. ${ }^{25}$ However, the highest birth weight in this study was that of a $6.55 \mathrm{~kg}$ female delivered to a -36 year old diabetic mother with 2 previous macrosomic babies. This was followed closely by another female fresh stillbirth which weighed $6.5 \mathrm{~kg}$ also delivered to a diabetic mother with a previous macrosomic birth. This could be due to strong multiple risk factors of macrosomia: obesity, diabetis mellitus and previous macrosomic deliveries in these mothers.

The three heaviest males each weighed $5.1 \mathrm{~kg}$, delivered to non obese, non diabetic mothers with no previous history of macrosomic births. The heaviest babies recorded in Enugu ${ }^{8}(1988)$ and Ife $^{23}(1991)$ weighed $5.5 \mathrm{~kg}$ each, more recently in Benin ${ }^{12}$ (2003), the biggest baby weighed $5.8 \mathrm{~kg}$. This trend is probably as a result of changes in the socioeconomic environment over the years resulting in the increasing incidence of macrosomia as earlier noted. ${ }^{12,22}$

In this study para 2 to 4 was most frequently associated with macrosomic births accounting for $41.2 \%$ of the mothers and in keeping with the report from Enugu, ${ }^{23}$ while $4 \%$ of the cases were grandmultiparous, in agreement with the Benin finding, ${ }^{12}$ but much lower than the 1988 earlier report from Enugu ${ }^{23}$. This could be as a result of declining incidence of grand multiparity in our environment. ${ }^{25,26}$ However, $27.4 \%$ of primigravidae in this study had macrosomic babies, much higher than the figures reported in other Nigerian studies, ${ }^{8,12,23,25}$ probably reflecting better maternal nutrition.

The elective caesarean section rate was $8.8 \%$, which was marginally lower than that of the control $(9.32 \%)$. This could be due to less recourse to elective caesarean delivery as it is thought to be too radical in the management of pregnancies complicated by fetal macrosomia. ${ }^{7}$ Expectedly, the emergency caesarean section rate was 3 times higher in the macrosomic cases than the control group in agreement with previous studies, ${ }^{12,23,27}$ probably due to higher incidence of cephalopelvic disproportion in the former. This may contribute to the increased morbidity among the macrosomic babies because fetal outcome in emergency caesarean delivery is incomparable to that of elective caesarean birth.

The overall perinatal outcome was worse for the macrosomic than the appropriate weight babies. The birth asphyxia rate at 1 -minute was $7.9 \%$ in macrosomic babies compared to $2.6 \%$ in the control group. This is in keeping with reports from other centres. ${ }^{2,8,23}$. Also admission into the special care baby unit (SCBU) was higher in the macrosomic babies $(29.9 \%)$, when compared to the appropriate weight controls $(2.82 \%)$. These may be as a result of the associated difficult labour, hypoglycaemic tendencies of the big babies and the mandatory policy of admitting babies weighing 
$4.5 \mathrm{~kg}$ and above in our centre. The perinatal mortality rate was 48/1000 live births in the macrosomic group. This was slightly more than 2 times higher than the rate in the control group, which was $23 / 1000$ live births. This pattern of high mortality rate is in keeping with findings of other workers, ${ }^{23}$ which contend that mortality even increases with gradation of macrosomia, with neonates weighing $5 \mathrm{~kg} \&$ above having the highest rate..$^{1,5}$ The neonatal morbidity (clavicular fracture, congenital malformations, birth asphyxia) rate was 3-4 times higher in the macrosomic than the control infants. Similar observations have been noted by other authors. ${ }^{1,2,5,8,12,23}$ This high morbidity rate in the macrosomic neonates could be related to the delivery process and the relative cephalopelvic disproportion. This could be reduced if detected earlier in the antenatal period and elective caesarean delivery offered.

\section{References}

1. Sheree L, Boulet MPH. Macrosomic births in the United States: Determinants, outcomes, proposed grades of risk. Am J Obstet Gynecol 2003; 188:1372-8

2. Vetr M. Risk factors associated with high birth weight deliveries. Ceska Gynekol 2005; 70(5): 347-54

3. Adetoro AA, Adedoyin MA. Maternal mortality and perinatal outcome for big babies. Trop J Obstet Gynaecol 1991; 9(1):41-43.

4. Ekabua JE, Agan TU, Iklaki CU, Ekanem El, Itam IH, Odey FA. Complications Associated with Macrosomic Fetus in Calabar, South Eastern Nigeria. MSJM 2005; 5(2): 5-7.

5. Mulik V, Usha TS. The outcome of macrosomic fetuses in low risk primigravid population. Int J Gynecol Obstet. 2003; 80:15-22.

6. Luigo R, Ghezzi F. Perinatal outcome of fetuses with birthweight greater than $4500 \mathrm{~g}$. An analysis of 3356 cases Euro J obstet \& Gynecol and Reprd Biol 2003; 109: 160-165.

7. Abudu 00, Awonuga $A O$. Fetal macrosomia and pregnancy outcome in Lagos. Intj Gynaecol Obstet 1989; 28:257-262.

8. Fasuba OB, Faleyimu BL, Ogunniyi SO. Perinatal outcome of macrosomic babies. Nig J Med 1991; (1):61-65.

9. Adinma JIB, Agbai AO. Fetal birth weights in Africa. J Obstet Gynaecol, 1995; 15:295-297.

10. ACOG Practice bulletin No.22. Washington (D.C.): American Col Obstet Gynaecol; 2000.

11. Bar J, Dver A. Brachial plexus injury and obstetric risk factors. Int J Obstet Gynecol 73 (2001) 21-25.

12. Onyiriuka AN. Macrosomic babies. Incidence and perinatal outcome. J Med Biomed Research 2003; 2(2): 35-41.

13. Yawn BP, Wollen P. Temporal changes in rates and reasons for medical induction of term labour 1980-86. Am J Obstet Gynecol 2001; 184:611-9.

14. Langer O. Fetal macrosomia. Etiologic factors. Clin Obstet Gynecol 2000; 43: 283-97.

\section{Conclusion}

There is a high incidence of fetal macrosomia in Port Harcourt in keeping with emerging global trends. There is also a corresponding increase in overall adverse perinatal outcome and in particular significantly higher perinatal morbidity and mortality among this group of neonates probably due to the rising incidence. Concerted efforts should therefore be made to review our policy on management of pregnancies with suspected macrosomic fetuses with more liberal use of elective caesarean section for such cases and improvement in intensive neonatal care and capacity building to march the rising challenges in our health care delivery.

15. Akani NA, John CT, Oruamabo RS. Seasonality and other variation trends in birthweights of $4000 \mathrm{~g}$ and above. A preliminary report from UPTH, Nigeria. Nig J Med 2006; 15(4): 395-396

16. Iron $\mathrm{O}$, Boulvain $\mathrm{M}$. Induction of labour for suspected macrosomia. Cochrane Data base Syst. Rev 2002 (2).

17. Fetal macrosomia. Practice Bulletin no.22 American College of Obstetricians \& Gynecologist; 2001: 1-11

18. Gregory KD, Henry OA. Maternal and infant complications in high and normal weight infants by method of delivery. Obstet Gynecol 1998; 92: 507-513.

19. World Health Organisation Expert Committee. Physical status: The use and interpretation of anthropometry. WHO Tech. Rep Ser. 1995; 854: 161-262.

20. Gregory KD, Henry OA, Ramicone E, Chan LS, Platt LD. Maternal and infant complications in high and normal weight infants by method of delivery. Obstet Gynecol 1998; 92: 507 513

21. Onyiriuka AN. Trends in birth weights of babies born in Benin City, Nigeria. Ann Biomed sci 2002; 1(2): 148-151.

22. Surkan PJ, Hsieh CC. Reasons for increasing trends in large for gestational age births. Obstet Gynecol 2004; 104: 720726 .

23. Megafu U, Ozumba BC. Obstetric complications of macrosomic babies in African women. Int J Gynecol Obstet 1988; 26: 197-202.

24. Ounsted $M$, Ounsted $C$. The fetal growth rate. Clin Develop med 1973; 46: 72-77

25. Milner RGD, Gluckman PD. Regulation of intrauterine growth. In: Gluckman PD, Heyman MA(Eds). Paediatrics and Perinatology: The Scientific Bases. $2^{\text {nd }}$ Edition, London: Arnold Publishers Itd. 1996: 284-289

26. Gharoro EP, Igbafe AA. Grandmultiparity: Emerging trend in a Tropical Community. Trop J Obstet Gynaecol 2001; 18(1):2730.

27. Simhayff N, Sheiner $E$. To induce or not to induce labour: A macrosomic dilemma. Gynecol and Obstet Investigation 2004; 58: 121-125. 